\title{
The Role of Mentoring in Transformational Change in Housing Association Mergers
}

\author{
Muhammad Rafique, \\ Nottingham University, United Kingdom
}

\begin{abstract}
Mentoring is a developing phenomenon and is widely used in the not-for-profit sector in the UK. Whereas, housing association mergers and the post-merger staff integration remain neglected areas of research. Qualitative data collected from 13 participants was analysed using constructivist grounded theory methodology within the constructivist research paradigm. The findings indicate that mentoring plays an important role in the initiation, execution and management of housing association mergers and transformational changes. It can influence the success or failure of a merger. The time line model presented here can enable housing officials, executive coaches and mentors in managing future mergers.
\end{abstract}

Keywords: Mentoring; Transformational Change; Post-Merger Integration; Housing Association Merger; Human Capital; Change Management 


\section{Introduction}

This paper discusses the role of mentoring in coping with organisational changes related to dynamic developments, such as mergers, in the housing association sector in the UK. Although the relationship between mentoring and transformation has been documented (Mezirow, 1991; Rogers, 2012), the housing association merger perspective remains a neglected area of research in the UK. Recent research shows that currently housing associations manage a far larger number of homes than ever before (Gulliver et al., 2011) and that the most recent trend is that of mergers. Literature on corporate mergers in general has shown that many mergers fail or at least are highly problematic. These problems include 'lowered commitment and productivity, increased dissatisfaction and disloyalty, high turnover among key managers, leadership and power struggle among the managers who stay, and, in general, a rise in dysfunctional work-related behaviours at all levels of hierarchy' (Buono and Bowditch, 2003, p. 3). Housing associations are required to be more efficient, compete for grants and undertake complex regeneration projects for community development (Lam, 2009).

In last five years, 171 housing associations entered into merger agreements. In 2018, there were 42 housing association mergers, including: Anchor Hanover (by the merger of Anchor Trust and Hanover Housing Association); Bromford (by the merger of Bromford and Merlin); and, Notting Hill Genesis (by the merger of Notting Hill Housing and Genesis Housing Association). As a result of constant merger activity in the last twenty-five years, average housing associations doubled in size from 955 homes to 1,816 homes, whereas market share amongst the largest twenty housing associations increased from 26 per cent to 30 per cent (Rees et al., 2012). On the other hand, the UK government has significantly reduced the capital commitment to build new homes. Housing Infrastructure Fund, a government capital grant programme, plummeted from $£ 11.4$ bn in 2009 to $£ 5.5$ bn in 2019.

Some larger housing associations own and manage over 50,000 homes, whereas the largest housing group Clarion, through a series of mergers now owns and manages 125,000 homes across 176 local authorities. With this level of activity, housing association mergers are important. To fully appreciate the housing association merger process, it is important to recognise the interventions used to deal with human factors. This in turn presents a clear rationale for this study.

The aim of this paper is to explore the role of mentoring in mergers and organisational changes in the housing association sector. More specifically, we analyse the experiences and perceptions of external mentors and housing officials with respect to learning and development in the housing sector and develop a time line model of merger process for practitioners expressing the role of mentoring in housing association mergers.

International Journal of Management and Applied Research, 2019, Vol. 6, No. 3 


\section{Theoretical Positioning and Research Context}

The field of mentoring is in the process of building its own research base by drawing on related disciplines that have an established theoretical grounding, such as adult learning, psychology and behavioural sciences (Cox, 2006; Rogers, 2012). In the adult learning context, mentoring supports self-reflection, which leads to self-awareness, self-acceptance and self-discovery (Griffiths, 2005); reflection is therefore the central process of transformative learning, and may result in transformational change (Mezirow, 1991). The relationship between transformational changes in the housing association sector in view of the potential demand for the learning, development and transformation of housing officials has not been examined. This paper seeks to contribute to theory development in the field of mentoring by presenting a time line model of merger process.

\subsection{Mentoring in the housing sector}

Mentoring in the housing sector is not a new phenomenon. Since October 2005 the Housing Diversity Network (HDN) has been providing mentoring in the housing sector. The initial mentoring focus of the programme was to address the lack of career opportunities for black and minority ethnic (BME) people within the housing sector. The scope of the mentoring programme has been widened to include all underrepresented staff working in the housing sector (HDN website). The HDN runs this mentoring initiative in conjunction with the Chartered Institute of Housing, and seems to be the only publicly available evidence that suggests that mentoring is used in housing associations to address the developmental needs of under-represented groups. This study attempts to address this gap in the literature.

\subsection{Transformational change}

Since mergers and acquisitions can readily change the nature and character of the organisations in question, they can be usefully conceived as a form of organisational transformation (Buono and Bowditch, 2003). Changes in housing associations following the merger or restructure seem to have transformational dimensions, and it is therefore important to explore the literature on transformational change. There is a substantial body of literature covering transformational change models, such as Lewin's (1951) three-step change model, Beckhard's (1969) change programme, Kotter's (1996) eight-step model for transformational change, and Latta's (2009) OC ${ }^{3}$ model of organisational change. Similarities and differences between these change models are presented in table 1 below. The recent models have included additional steps to reflect changing organisational structures and to incorporate organisational culture, even though the concepts introduced by Lewin (1951): unfreezing the current situation, changing and refreezing the new status quo seem to form basis of these models.

International Journal of Management and Applied Research, 2019, Vol. 6, No. 3 
Table 1: Similarities and differences between change models

\begin{tabular}{|c|c|c|c|}
\hline $\begin{array}{l}\text { Lewin } \\
(1951) \\
\text { 3-Step } \\
\text { model }\end{array}$ & $\begin{array}{l}\text { Beckhard (1969) } \\
\text { Change } \\
\text { programme }\end{array}$ & $\begin{array}{l}\text { Kotter (1996) } \\
\text { 8-Step change model }\end{array}$ & $\begin{array}{l}\text { Latta (2009) } \\
\text { OC }^{3} \text { model of } \\
\text { organisational change }\end{array}$ \\
\hline Unfreezing & $\begin{array}{l}\text { Analysing present } \\
\text { condition }\end{array}$ & $\begin{array}{l}\text { Sense of urgency; } \\
\text { Create guiding } \\
\text { coalition }\end{array}$ & $\begin{array}{l}\text { Cultural analysis of } \\
\text { readiness; } \\
\text { Shaping vision }\end{array}$ \\
\hline Changing & $\begin{array}{l}\text { Setting goals for } \\
\text { future; } \\
\text { Plan of action }\end{array}$ & $\begin{array}{l}\text { Develop vision and } \\
\text { strategy; } \\
\text { Communicate the } \\
\text { vision; } \\
\text { Empower employees; } \\
\text { Generate short term } \\
\text { wins }\end{array}$ & $\begin{array}{l}\text { Informing change } \\
\text { initiatives; } \\
\text { Reflecting culture in } \\
\text { implementation; } \\
\text { Embodying cultural } \\
\text { intent; } \\
\text { Cultural mediation of } \\
\text { implementation }\end{array}$ \\
\hline Refreezing & $\begin{array}{l}\text { Implementing the } \\
\text { plan }\end{array}$ & $\begin{array}{l}\text { Improve on the } \\
\text { changes; } \\
\text { Institutionalise new } \\
\text { approaches }\end{array}$ & $\begin{array}{l}\text { Moderating outcomes of } \\
\text { change; } \\
\text { Documenting collateral } \\
\text { effects }\end{array}$ \\
\hline
\end{tabular}

The drawbacks of the transformational change models are pointed out by some scholars, such as: Burnes (1996), Cinite et al (2009), and D'Ortenzio (2012). These models are based on the assumption that organisations operate under stable conditions and can move from one stable state to another in a planned manner, therefore might not be useful in turbulent business environments. In his critical analysis, D'Ortenzio (2012) asserted that Lewin's model ignores the role of power and politics; and appears too simplistic and mechanistic. For Kotter's model to be successful, all of the eight stages must be worked through in order; skipping even a single step could be problematic; and the model could be seen as a checklist rather than a process, as intended by Kotter.

Transformational change models do not seem to take into consideration the transformative learning of staff during the process of change in the organisational context. The focal point of these transformational change models appears to be the management of staff rather than the development of staff. Additionally, these models are directed at organisations in need of change but otherwise operating in a stable environment, which is not the case with housing associations.

\subsection{Effectiveness of mentoring}

Mentoring is a developing phenomenon and mentoring arrangements can be found in many aspects of life. A growing body of academic and practitioner literature supports

International Journal of Management and Applied Research, 2019, Vol. 6, No. 3 
the "popular perception [that] mentoring offers considerable value to individuals and organizations' according to Hezlett and Gibson (2005, p. 446). Mentoring is 'more readily available as an antidote to stress than previously considered' (Kram and Hall, 1989, p. 493). Mentoring relationships, according to Kram and Hall (1989), are perceived as more desirable during times of workplace stress resulting from corporate downsizing. As the focus of this study is specific to mentoring in mergers and transformational change within the workplace context, other mentoring studies, such as youth mentoring and student-faculty mentoring are not explored in this paper.

Traditional mentoring relationships involve a mentor and a protégé, who are bound together by close ties, engaging in an exchange that involves both career-related and psychosocial resources (Baugh and Fagenson-Eland, 2005). However, they suggest that external mentoring can lead to more independence and greater career self-efficacy, which is important in changing organisational circumstances such as mergers.

Additionally, the individual outcomes can include learning, self-awareness and social skills, while the organisation can benefit from retention, organisational learning and innovation. In their proposed model, Kram and Higgins (2012) seem to acknowledge the fact that for mentoring to stay relevant in modern times, it has to change and adapt.

\section{Methodology}

This paper is positioned within the constructivist research paradigm, with constructivist grounded theory chosen as the approach for analysing data collected through semi-structured interviews. The participants of the study are employees of housing associations that have gone through a merger or any other form of business partnership that has resulted in changes to the group structures of those housing associations.

Charmaz (2006) suggests that the comparative methods should be used at all levels of data analysis, including comparing data with data, data with codes and codes with codes. The analysis of data and emerging ideas throughout the enquiry enables integration and streamlining of data collection and analysis.

Thirteen participants were selected from three groups: (1) executive coaches, (2) senior housing executives, and (3) housing officers. Five executive coaches, two male and three female, with experience of both for-profit and not-for-profit sectors participated in this study. These coaches were identified via a considerable search of housing- and coaching-related websites. All the coaches were well known within the coaching and mentoring industry and endorsed by their high-profile clients. They had experience of providing coaching, mentoring, training or transformational change programmes in the housing sector in England and Scotland.

Five senior housing executives, two male and three female, with experience of housing association mergers participated in this study. Three of these housing executives were

International Journal of Management and Applied Research, 2019, Vol. 6, No. 3 
chief executives, and two were senior directors in housing associations that have gone through at least one merger.

Three male housing officers, two at officer level and one assistant manager participated in this study. They were referred to as front-line officers, as their roles involved face-to-face contact with tenants. All the officers had experienced two housing association mergers.

\section{Results}

In the HDN mentoring programme, middle to senior managers from under-represented groups within a housing association is mentored by senior executives from another housing association. This programme does not cater for the developmental needs of senior housing executives responsible for initiating and managing change, even though it develops middle to senior managers who have responsibility for implementing change in their departments.

In executive mentoring, senior housing officials receive mentoring from external coaches. These coaches share their knowledge and experience which is accumulated from the public and private sectors. This type of mentoring relationship provides an out-of-sector perspective for the housing executives which can be helpful whilst evaluating strategic options. Peer mentoring in the housing associations seems to focus on streamlining the front-line services following the merger. In this mentoring arrangement, best practices at operational level are shared with staff from the recently merged housing association. Figure 1 illustrates the diversity and complexity of mentoring initiatives in the housing associations. The focus codes that underpin the mentoring themes are constructed from the perceptions and experiences of coaches, housing executives and front-line officers.

\section{Figure 1: Focus codes}

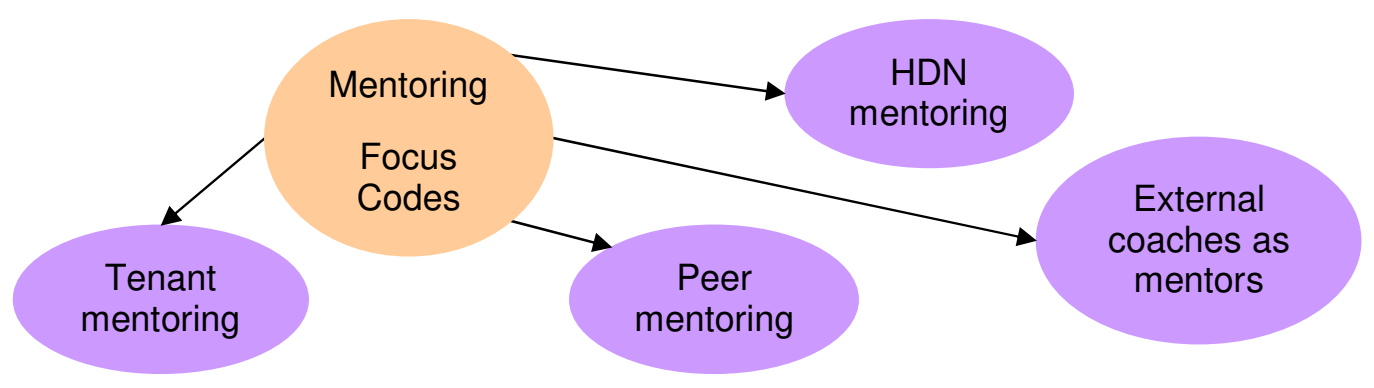

The mentoring arrangements mentioned so far, are aimed at the development of housing officials. Induction, peer and out-of-sector mentoring do contribute to the effective and efficient management of housing association mergers. However, in some cases, housing associations train and mentor their tenants, who are not the employees of the housing association. The aim of mentoring tenants into employment is to help 
them learn a trade and to improve their employability. Tenant mentoring helps in tackling unemployment within the social housing sector, and contributes to the transformation of the neighbourhoods that the housing associations serve.

\subsection{HDN mentoring programme}

The HDN started providing mentoring within housing associations in 2005. At that time, mergers between housing associations were entering into a phase where different housing groups had started merging to form bigger housing groups; for instance, the merger of the Circle 33 Housing Group and the Anglia Housing Group in 2005. However, the HDN mentoring programmes did not initially focus on housing association mergers or transformational change. The mentoring was to address the under-representation of BME groups in housing association management. This study did not find a shift in the focus of the mentoring programme to incorporate mergers or transformational changes.

Housing executives are required to have skills and experience in a particular area before applying to become mentors. A database of potential mentors and mentees is maintained by the HDN. By introducing mentors with certain specialities to their potential mentees, who aspire to develop those specialities, the HDN plays the role of a matchmaker. But sometimes the specific requirements of the mentees cannot be matched from within the pool of existing mentors. In these cases, the potential mentors are contacted through their professional networks and invited to offer mentoring services. For example, Executive D was contacted by the Chartered Institute of Housing to provide mentoring. "I certainly have done mentoring of people from other organisations, sponsored by the Chartered Institute of Housing, but this tends to be more on request (Executive D)".

The mentors shared their wisdom, tools and techniques with the mentees; subsequently, they received feedback from the mentees about the usefulness of these tools and techniques in different organisational settings. Learning taken from the evaluation and reflection was incorporated in the next round of mentoring.

One of the significant features of the HDN mentoring programme is that the mentor and the mentee are both from the housing sector but from different housing associations. Such an arrangement seems ideal to help mentees in dealing with workplace problems they may not want to share with their own managers (Dymock, 1999). In spite of this, Hatmaker et al. (2011) argue that organisational and task-based knowledge is tacit, grounded in the experience of more senior co-workers, supervisors and upper-level managers, and ties should be developed to access this information. This is not the case with HDN mentoring, as the mentor and the mentee are not coworkers. However, Baugh and Fagenson-Eland (2005) argue that nothing in the definition of mentoring suggests that the mentor and the mentee must be employed in the same organisation.

In summation, the HDN mentoring programme is focused on developing future leaders. The programme does not have a mechanism in place to facilitate the

International Journal of Management and Applied Research, 2019, Vol. 6, No. 3 
mentoring of senior executives. The housing sector is significantly changing, and housing associations are increasingly becoming large and complex organisations. Senior housing executives who are leading their housing associations through a merger or transformational change might benefit from being mentored through this process. The HDN mentoring programme develops managers to implement change in their departments (but only if they belong to an under-represented group). It does not seem to help senior executives to initiate and manage organisational change. This gap is being filled by external coaches, who act as mentors to senior housing executives. This arrangement is discussed in the next section.

\subsection{External coaches acting as mentors}

Some participant senior housing executives were receiving mentoring from external coaches. One of the emerging themes was 'the development and growth of senior managers'. However, the mentoring agenda, according to the coaches, was not about the personal or professional development of the housing executives in readiness for the next promotion, but about dealing with the challenges at hand. The underlying purpose of mentoring varied from identifying strategic direction, learning from the private sector or gaining an external perspective. This section reflects the experiences and observations of external coaches acting as mentors.

It comes across from one of the coach's accounts that some senior housing executives are struggling to find a strategic direction in the wake of organisational challenges. "There is a bit about, in these challenging times, how do you help senior management actually have a vision within an organisation? (Coach A)".

The external coaches, who are the mentors in this arrangement, have broader experience, which includes working in and providing mentoring for different sectors, including the for-profit sector and entrepreneurship. This experience seems to have appealed to the senior executives in choosing their mentors. The coaches explained that they were approached by senior housing executives because "we also work in [the] private sector, so we know [how the private sector works]" (Coach C).

Interestingly housing executives are looking to the private sector with a view to understanding how organisational change is managed as a result of a merger or restructure. This out-of-sector perspective enables housing executives to address some of their own issues effectively. In some cases the quest for innovation and entrepreneurship seems to be the motive behind the choice of mentor, as one of the participants explained: "Well, the reason that people may approach us [for mentoring] is because we have managed businesses as well (Coach E)". Other reasons included the 'nurturing skills of the mentors' and the 'objectivity' they could offer, according to Coach E.

Newly appointed or promoted senior housing executives can benefit from the nurturing skills of the mentors by developing ideas for revenue generation. At the same time, experienced housing executives wishing to launch new initiatives would find the nurturing skills and objectivity of the mentors useful. External coaches provide not

International Journal of Management and Applied Research, 2019, Vol. 6, No. 3 
only a safe environment to explore fresh ideas but also an objective viewpoint about the workability and feasibility of any such ideas. Furthermore, they can help the senior executives in nurturing those ideas.

Cases of executives seeking mentoring from external coaches for their nurturing and entrepreneurial skills, as described by the participants, could be interpreted in a number of ways: (1) the executives could be considering incorporating some of the practices adopted by the private sector; (2) it could be seen as a skills deficit in the areas of entrepreneurship and change management among the current mentors within the housing sector; or (3) it could possibly be due to the commercial sensitivity and confidentiality necessitated by the complex organisational change within the housing sector.

The scope of this out-of-sector mentoring seems to be more wide-ranging than traditional mentor-protégé relationships. This type of mentoring provides additional confidentiality for commercially sensitive issues, and also provides the mentees with an opportunity to benefit from the mentors' experience in exploring innovative entrepreneurial initiatives.

Findings of this study add to the growing body of mentoring literature. Reduction in grant funding demands that housing executives identify innovative ways to manage the finances of their housing associations, for example launching new income generating initiatives such as 'for profit arms of the housing associations' or cost saving initiatives for instance mergers or reorganisations. The sensitive nature of such financial and commercial interests of the housing associations would not allow a peer mentoring relationship based on openness and trust.

\subsection{Peer mentoring as part of post-merger staff induction}

Peer mentoring in the housing associations was initially coded under job shadowing, buddy system and peer mentoring. These codes were later on collapsed into the "peer mentoring' focus code because of the similar nature of these activities. In addition to peer mentoring, housing associations involved in this study also used induction mentoring as part of the post-merger staff induction programmes. As the housing association mergers resulted in some sort of restructure, one of the aims of this induction mentoring was to familiarise staff with the new organisational structure.

We had induction; you put a couple of days aside and obviously, because you are new, you get to be introduced to all the people working in different departments and find out exactly what is going on in every department (Officer B).

The induction mentoring helps staff in understanding the roles and responsibilities of their colleagues working in different departments. The housing associations use this opportunity to make staff aware of the culture, vision and strategic objectives of the housing group. The executives described the mentoring programme as a mechanism to welcome new arrivals into the housing group and share the strategic vision with them, right from the beginning.

International Journal of Management and Applied Research, 2019, Vol. 6, No. 3 
We have a structured induction programme, where [staff from the merged housing association] come in, they meet the staff, they have a number of different presentations about the key parts of the organisation and then [have a] meeting [with] the various teams. So they spend a little bit of time with each of the teams just to see what they all do, to get to know people (Executive P).

The structured nature of the induction mentoring highlights the importance of teamwork in housing associations. Understanding the roles and responsibilities of different teams through presentations and then meeting and spending time with colleagues from different teams should enhance team cohesion. Through the induction programme, the executives of this study wished the colleagues from the merged housing associations to feel welcomed to the new housing group. There was an opportunity to get to know colleagues from other departments so there was a sense of belonging after a tiresome change period, according to the officers. Officer B mentioned job security as a reason for concern and uncertainty during the course of the merger.

We were concerned ... it [the change] was daunting ... you could see on peoples' faces ... managers were saying business as usual, but we knew it wasn't business as usual ... it was frustrating, actually (Officer B).

Human factors such as stress and anxiety arising from uncertainty and concerns about job security during the course of a housing association merger appear to have been allayed as a result of the induction mentoring. "It is important for us to see the smooth transition ... we managed our processes very smoothly (Executive P)".

In addition to the induction mentoring, the housing associations offered peer mentoring for the new staff after the merger or restructure. This peer mentoring was comparatively less formal, longer term and only available to the non-managerial staff. The arrangement was referred to as the 'buddy system' or 'job shadowing' by the senior housing executives and officers. "So we were spending a lot of time with mentors, a buddy kind of system. You really learn the process; you shadow the housing officer, the income officer, to see what they do (Officer B)".

As part of the peer mentoring, the mentors demonstrated their working practices, record-keeping requirements and their interaction with the tenants. It is important to clarify the distinction that participants of this study who received peer mentoring were not newly appointed, but they were new to the merged housing group. Allocating time with the preceptor and welcoming new members of staff through supportive and friendly interactions was also part of the induction process.

Two modes of peer mentoring, following the merger of housing associations, emerged from the data. In the case of a housing association joining the housing group, the processes and procedures of the group prevailed. In the case of a 'merger of equals', where two housing groups merged to form a bigger group, the better-quality procedures were adopted. Senior executives participating in the study were quite open

International Journal of Management and Applied Research, 2019, Vol. 6, No. 3 
about the inconsistency in the quality of the processes and procedures among different housing associations and groups.

One part of the organisation [one housing group] is much more forward in terms of its processes, and its procedures are much more in line with the regulators, ... [whereas the other housing group] tended to be somewhat less concerned about the constitution and the regulation. So a lot of the systems that have been on one side of the organisation have been implemented in the other side (Executive A).

Implementing the 'better-quality' procedures of one housing group in the newly merged other group caused some disquiet and resistance. According to Executive A, "the affected staff started to say "we are being taken over ... we are being told what to do" ... but the fact of the matter is the systems were better, and you have to go with what is best'.

This indicates that peer mentoring in the merger of two housing groups might be more challenging than in a housing association merging with a group. This distinction, in our view, is important because of the potential staffing issues such as tension and conflict during peer mentoring following the merger between the two housing groups.

This study adds to two different aspects of the mentoring literature, from the housing association perspective. Firstly, peer mentoring is not only deemed relevant for newly appointed staff, but some housing associations use it after the merger as well. Secondly, in a merger situation, peer mentoring can be seen by the participants negatively or positively, depending on the relative position of their employer. In the case of a small housing association merging with a large group, peer mentoring is valued by staff according to the data collected for this study. Whereas, in a merger of equals, the employees receiving peer mentoring to learn new procedures after the merger might show antipathy towards it. This study adds to the peer mentoring literature, the element of apprehension among peers in the merger of equals and its adverse impact on the post-merger peer mentoring relationships.

\subsection{Mentoring tenants into employment}

Housing association mergers and transformational changes are linked to the provision of better-quality, cost-effective and efficient services for tenants. Housing executives are acutely aware of their responsibility to the tenants. Their priorities included: local involvement and providing neighbourhood solutions (Executive E), making a difference to the tenants' lives (Executive C), and addressing the housing needs of tenants (Executive B). In one case, the commitment was clearly matched with tangible actions. Executive P reiterated the pledge: "Everything we do is ploughed back into the very neighbourhood that we serve and the homes that we serve and the tenants we serve (Executive $P$ )".

As part of their transforming neighbourhoods initiative, the housing association mentored tenants into employment. Some of the properties owned and managed by this housing association are situated in the top ten most deprived areas in the UK. The

International Journal of Management and Applied Research, 2019, Vol. 6, No. 3 
housing association is now using mentoring to help their unemployed tenants. The initiative was led by a manager who had the support of the board of directors of the housing association. The participant executive described the initiative as follows:

The manager has taken real steps to get people into employment, people who have been long-term unemployed. [He] provides them with a job, [and] mentors them into that job to keep them going, to make sure that they get properly trained (Executive $P$ ).

As part of this initiative, tenants in long-term unemployment were offered on-the-job training and mentoring to equip them with employability skills. When the manager felt that these tenants were fully trained, then they were supported with their job application and mentored for the interview process. Describing the outcome of the mentoring programme, the executive said: "We've now sustained full-time permanent employment for nineteen individuals (Executive $P$ )". Mentoring tenants into employment offered corporate rewards for the housing association. Additionally, the mentees become ambassadors of the housing association.

\section{Discussion}

Mentoring plays an important role in the initiation, execution and management of housing association mergers and transformational changes. Mentoring can have an impact on the success or failure of a housing association merger. One possible explanation for the high success rate of housing association mergers found by this study is the degree of staff and systems integration at the post-merger stage. During the merger process in some cases, an open-door policy was observed by the participant housing executives to respond to employee concerns. Induction and peer mentoring were used to ensure a smooth transition. This study shows that mentoring (peer and induction) used in housing associations have a positive impact on post-merger integration.

Post-merger integration, according to some authors (e.g. Buono and Bowditch, 2003; Bauer and Matzler, 2014) can be the decisive success factor of a merger. According to Buono and Bowditch (2003) the first hundred days following the merger offer a window of opportunity in which employees are more susceptible to change. Bauer and Matzler (2014), after reviewing the findings of a number of studies, concluded that there is empirical evidence for either a positive, negative, or non-significant relationship between the speed of integration and merger performance. It was found that induction mentoring and peer mentoring were used for post-merger integration. The transformational change programmes that were used in housing associations were of twelve to eighteen months' duration.

The merger failure and partial merger failure examples provided by housing executives showed that the level of post-merger integration dictated whether the failure would result in a de-merger or in the merged housing associations staying together. The housing association that ended up de-merging in one of the case studies focused on a specific segment of the market and so was kept separate after the merger, rather than

International Journal of Management and Applied Research, 2019, Vol. 6, No. 3 
integrating it with the mainstream housing provision of the rest of the housing group. So it is possible that a greater focus on post-merger integration could reduce merger failures in the housing association sector.

\subsection{Branding of mentoring services}

Mentoring appears to be widely used and understood because of the growth of HDN registered housing associations. HDN mentoring programmes in housing associations are designed to help in the personal and professional development of both the mentor and the mentee. Interestingly, external mentoring was cherished and actively promoted. In these cases housing executives received mentoring to find innovative solutions to the issues faced by their housing associations. External mentoring was utilised in some cases to help senior housing executives to manage organisational change effectively or to rediscover a strategic vision and perspective in the rapidly changing housing sector. The advantages of this out-of-sector mentoring include gaining innovative ideas, entrepreneurial acumen and reflective space. However, executive mentoring appears to be most suitable for senior executives who are taking their housing associations through organisational change. All participant housing executives confirmed that mentoring would form part of the post-merger staff development policies.

\subsection{Post-merger integration minimises merger failures}

Merger failures in the housing association sector have not been empirically examined. This study found evidence of some merger failures. One housing executive reported a merger as a partial failure, whereas another executive experienced a full merger failure. Partial failure was described as one in which the promises made by the housing group about investment in the merging housing association's assets were not delivered in full. However, because of the integration of systems and processes, it was not logistically possible for the housing association to de-merge despite the disappointment. In another case, the operations and systems of the merged housing association were kept separate from the rest of the housing group. At a later stage, the housing association de-merged from the group which was seen as a merger failure by the participant housing executive. The principal difference between a partial and a full merger failure in these two cases was the level of post-merger integration.

Housing associations use different forms of mentoring to enhance post-merger integration, including induction mentoring and peer mentoring. In the light of the different interpretations of mentoring discussed earlier, it is plausible to assume that the term 'new staff induction' was referred to as 'induction mentoring' by the participants. However, the structure and delivery of induction programmes shows the elements of embedded mentoring in the post-merger induction.

Peer mentoring might ease merger related stress and anxiety or it might aggravate it. The nature of business combination as a result of the merger seems to determine the impact of peer mentoring. Portner (2005) demonstrates that embedding mentoring in the induction programmes can enhance post-merger integration. Mergers in the

International Journal of Management and Applied Research, 2019, Vol. 6, No. 3 
housing association sector do fail but senior housing executives can keep the failure rate relatively low through post-merger integration and by managing the expectation gap of staff in the case of merger of equals. Deep-rooted stress and anxiety experienced by housing officers during the merger can intensify when they have to learn and adapt to the processes and procedures of the other housing group, which they joined on equal terms. Housing officers take solace from learning the processes and procedures from their new colleagues, in the case of a housing association joining a group.

\section{Theoretical Framework}

In this section the theoretical framework is presented in the form of a time line model of merger process. This model is divided into four stages: before merger (merger considered but partners not identified); pre-merger (immediately before a planned merger); during merger and post-merger.

Figure 2: Merger Process: A time line model

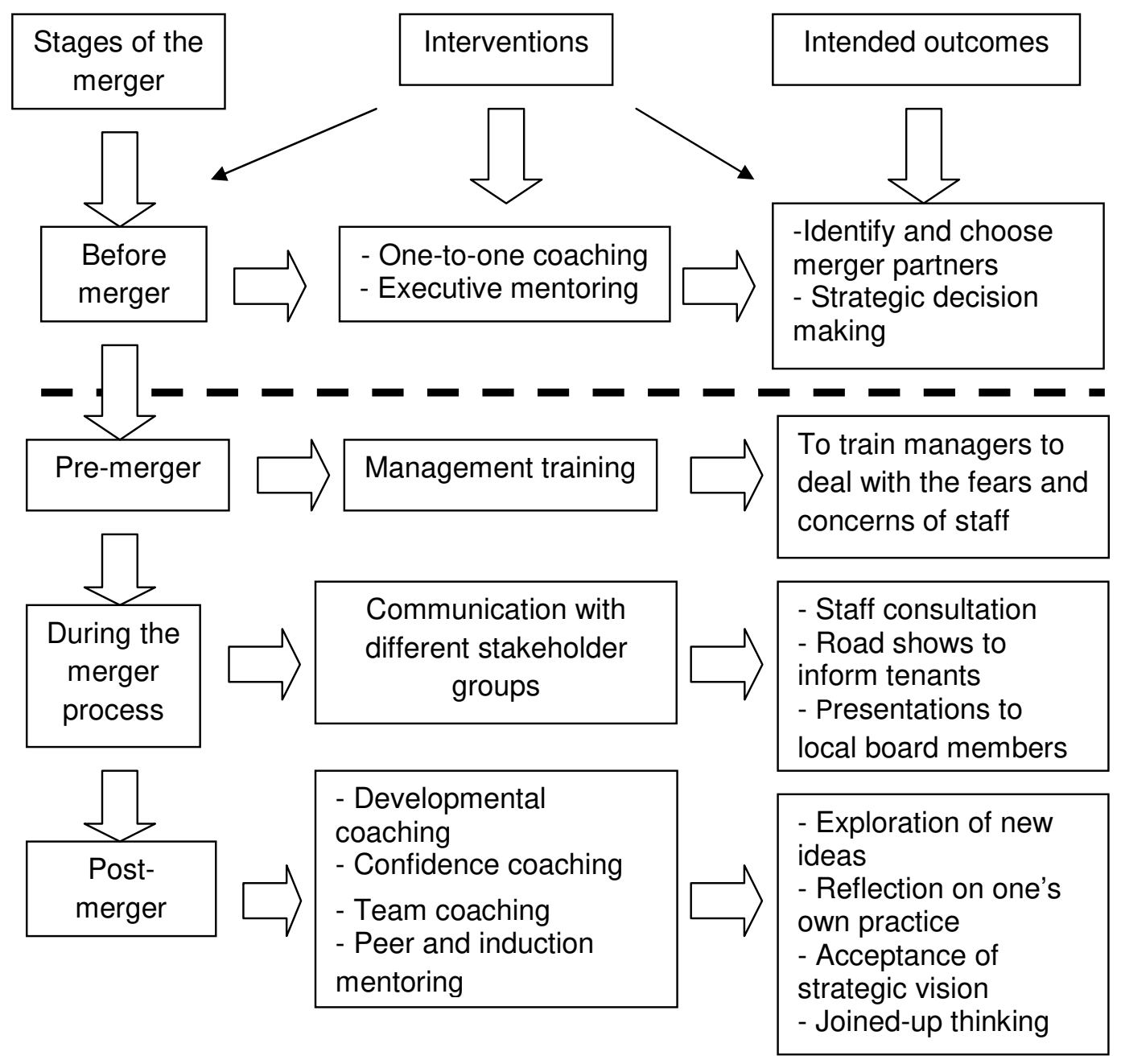

International Journal of Management and Applied Research, 2019, Vol. 6, No. 3 


\subsection{Before Merger Stage}

Before entering a merger agreement, senior housing executives have to make strategic decisions about the future of their housing association. The right choice of merger partner is extremely important. The incentives and promises have to be assessed by taking into consideration the history, reputation and motives of the potential merger partners. Based on the commercial sensitivity, HDN mentoring is not appropriate at a strategic level. Housing executives trust the independence and professionalism of external coaches for executive mentoring.

The decision to merge affects the lives or livelihoods of a variety of stakeholders, including: existing and potential tenants, staff, suppliers, sub-contractors and other neighbourhood agencies. So, a clear and transparent merger decision is vitally important. Finding the right merger partner can take a long time. One housing group was searching for a partner for over two years before entering a merger agreement.

\subsection{Pre-merger Stage}

The pre-merger stage is distinct from the 'before merger' stage. The pre-merger stage in this model starts after the formal merger agreement has been reached. At this stage, the decision is communicated to all staff members via intranet announcements, staff newsletters and at employee road shows. Both housing associations / housing groups carry on serving their tenants as normal but start planning the logistics of the merger. To understand the operational practices of the merger partners, reciprocal site visits are arranged. In some cases, exchange staff secondments are also organised to enhance a smooth transition.

The model reflects the findings of this study, according to which mentoring is not used at the pre-merger stage of the merger. Human resources departments offer some training for managers to enable them to deal with the fears and concerns of staff members.

\subsection{During the merger Stage}

The 'during the merger' stage is the most chaotic, as at this stage reality hits home. The executives manage a transformational change whilst trying to keep the disruption to tenant services to a minimum. Senior housing executives convene meetings with tenant groups to explain the decision and to reassure them about the quality and consistency of tenant services. At the same time, the executives have to deal with staff morale and convince them 'it is business as usual'. Staff morale is lowest at this stage of the merger according to the data. Some experienced staff members who do not want to go through the uncertainty, take early retirement or change jobs. New staff members are not recruited as post-merger organisational structures are not finalised at this stage. Some staff members go on stress-related sick leave.

Senior executives engage in staff consultation in an effort to allay their fears and uncertainties. The open door communication policy may have negative impacts too. The executives encourage staff 'to ask questions, even though they might not have the answers to them'. If the questions are not answered in a satisfactory manner, the

International Journal of Management and Applied Research, 2019, Vol. 6, No. 3 
concerned staff members sometimes conclude that "management has something to hide'. They may see the staff consultation and engagement exercise as sham.

Senior executives understand the stress and uncertainty experienced by staff members, but they maintain that some of the questions relate to the post-merger restructure which will be finalised at a later stage in consultation with the merger partners. Therefore, even the executives may not know the answers to those questions. This can lead to all sorts of interpretations and rumours. In addition, the nature and frequency of questions can change on a daily basis depending on what staff members hear from each other and who they choose to believe. Senior executives have to concentrate on the merger process and cannot engage in staff consultation on a daily basis. The unanswered questions and the inherent uncertainty add to the mistrust between staff and senior executives. Mentoring during the merger process stage are not used as per this study for the following reasons: (a) staff availability: fewer, over-worked, stressed staff members are responsible for delivering day-to-day services to tenants, hence cannot be made available to attend mentoring sessions (b) the element of mistrust discussed earlier (c) the focus of the management is to deliver the merger within a set timescale, so staff development at this stage is not a priority (d) mentoring might not provide the answers sought by staff members.

\subsection{Post- merger Stage}

Mentoring in various forms are used by the housing associations at the post-merger stage. Executive mentoring for the development of first time directors following the post-merger restructure: induction mentoring to infuse housing group values; peer mentoring to support staff through the changeover and a combination of mentoring interventions as part of transformational change programmes.

This time line model provides the practitioners (coaches and housing officials) with evidence on which to base their services and provides researchers with an opportunity to develop a formal theory. This model enables coaches to reflect on their own practice, how mentoring is used in housing association sector mergers and how the time line model can be integrated into their mentoring services.

\section{Conclusion}

This paper set out to explore the role of mentoring in relation to transformational changes, with particular reference to housing association mergers. This is probably the first study to explore the role of mentoring in housing association mergers. The findings of this study indicate that mentoring plays a crucial role in managing transformational changes when housing associations merge.

Mentoring contributes to the learning, development and post-merger integration of housing officials. Integration can keep the merged housing association together, thus reducing merger failures in housing associations.

International Journal of Management and Applied Research, 2019, Vol. 6, No. 3 


\subsection{Limitations and future research}

Several limitations were reflected upon within this study. Not being able to interview middle to senior managers in the housing associations can be seen as a weakness. At the time of data collection, the housing associations were in the process of post-merger internal restructuring, and middle to senior managers were reapplying for jobs under the new structure. The senior housing executive did not allow me access to middle to senior managers. This staff group might have held differing perceptions and experiences and contrasting opinions as compared to the groups that did participate.

The process adopted for the recruitment of front-line officers had weaknesses. It proved difficult to contact the front-line officers directly, as their contact details were not provided on housing association websites. This reflects the nature of employment structures in housing associations. So the contact details of the front-line officers were obtained through a managerial-level gatekeeper. Although this method of recruitment was pragmatic, it might have allowed the gatekeeper to use his judgement about the suitability of potential participants.

This study took place in the housing association sector, so the results of this study are not necessarily transferable, and this may be perceived as a limitation. 13 participants were interviewed which is not a representative sample of the sector as a whole.

For the future, this research offers a potential springboard for numerous possible research paths, which might help mentoring to establish their theoretical bases and add to merger theories. These research opportunities are summarise below:

- The experiences and presumptions of middle to senior managers are missing from this study. Perhaps a comparative study that does include this specific group would add to the time line model presented in this paper.

- All the housing executives affirmed that mentoring would form part of their future leadership development programmes. Further longitudinal studies would throw more light on the impact of this inclusion on the future direction of housing association mergers.

- This study found that one housing association merger failed, whereas another one was seen as a partial failure by the housing executive and only survived because of systems and processes integration. One recommendation for the future, therefore, would be a detailed analysis of housing association mergers where de-mergers were averted by post-merger integration.

\section{References}

1. Bauer, F. and Matzler, K. (2014), "Antecedents of M\&A success: The role of strategic complementarity, cultural fit, and degree and speed of integration", Strategic Management Journal, Vol. 35, No. 2, pp. 269-291. https://doi.org/10.1002/smj.2091

International Journal of Management and Applied Research, 2019, Vol. 6, No. 3 
2. Baugh, S. G., and Fagenson-Eland, E. A. (2005), "Boundaryless mentoring: An exploratory study of the functions provided by internal versus external organisational mentors", Journal of Applied Social Psychology, Vol. 35, No. 5, pp. 939-955. https://doi.org/10.1111/j.1559-1816.2005.tb02154.x

3. Beckhard, R. (1969), Organisational development: Strategies and models, Reading, MA: Addison-Wesley.

4. Buono, A. F., and Bowditch, J. L. (2003), The Human Side of Mergers and Acquisitions: Managing Collusions Between People, Cultures and Organisations, Washington: Beard Books.

5. Burnes, B. (1996), "No such thing as ....a "one best way" to manage organizational change", Management Decision, Vol. 34, No. $10, \quad$ pp. $11 \quad-18$. https://doi.org/10.1108/00251749610150649

6. Charmaz, K. (2006), Constructing Grounded Theory: A Practical Guide Through Qualitative Analysis, London: Sage.

7. Cinite, I., Duxbury, L. E., and Higgins, C. (2009), "Measurement of perceived organizational readiness for change in the public sector", British Journal of Management, Vol. 20, No. 2, pp. 265-277. https://doi.org/10.1111/j.14678551.2008.00582.x

8. Cox, E. (2006), "An adult learning approach to coaching", In: M. Grant and R. Stober (eds), Evidence Based Coaching Handbook, Hoboken, NJ: Wiley \& Sons, pp. 193-217.

9. D'Ortenzio, C. (2012), Understanding change and change management processes: A Case study. PhD thesis, Australia: University of Canberra.

10. Dymock, D. (1999), "Blind date: A case study of mentoring as workplace learning", Journal of Workplace Learning: Employee Counselling Today, Vol. 11, No. 8, pp. 312-317. https://doi.org/10.1108/13665629910300496

11. Griffiths, K. (2005), "Personal coaching: A model for effective learning", Journal of Learning Design, Vol. 1, No. 2, pp. 55-65.

12. Gulliver, K., Handy, C., and Morris, J. (2011), Beacons of Hope: The Historic Role of Housing Associations Tackling Poverty, Disadvantage and Inequality. Birmingham: Human City Institute.

13. Hatmaker, D. M., Park, H. H., and Rethemeyer, R. K. (2011), "Learning the ropes: Communities of practice and social networks in the public sector", International Public Management Journal, Vol. 14, No. 4, pp. 395-419. https://doi.org/10.1080/10967494.2011.656051

14. Hezlett, S. A., and Gibson, S. K. (2005), "Mentoring and human resource development: Where we are and where we need to go", Advances in Developing Human Resources, Vol. 7, No. 4, pp. 446-469. https://doi.org/10.1177\%2F1523422305279667

15. Kotter, J. P. (1996), Leading Change, Boston: Harvard Business School Press.

International Journal of Management and Applied Research, 2019, Vol. 6, No. 3 
16. Kram, K. E., and Hall, D. T. (1989), "Mentoring as an antidote to stress during corporate trauma", Human Resource Management, Vol. 28, No. 4, pp. 493-510. https://doi.org/10.1002/hrm.3930280405

17. Kram, K. E., and Higgins, M. C. (2008), “A new approach to mentoring”, The Wall Street Journal, [Online] available from: https://www.wsj.com/articles/SB122160063875344843 [Accessed on 19 June 2012].

18. Lam, T. Y. M. (2009), “ A total change management model for successful growth of housing associations", International Journal of Housing Markets and Analysis, Vol. 2, No. 3, pp. 263-275.

19. Latta, G. F. (2009), “A process of organizational change in cultural context (OC3 Model)", Journal of Leadership \& Organizational Studies, Vol. 16, No. 1, pp. 1937. https://doi.org/10.1177/1548051809334197

20. Lewin, K. (1951), Field Theory in Social Science. New York: Harper \& Brothers.

21. Mezirow, J. (1991), Transformative Dimensions of Adult Learning. San Francisco: Jossey-Bass.

22. Portner, H. (2005), Teacher Mentoring and Induction: The State of the Art and Beyond. Thousand Oaks, CA: Corwin.

23. Rees, J., Mullins, D., and Bovaird, T. (2012), Partnership working. Third Sector Research Centre Research Report (no. 88).

24. Rogers, J. (2012), Facilitating Reflective Learning: Coaching, Mentoring \& Supervision ( $2^{\text {nd }}$ ed.). London: Kogan Page. 